\title{
SINE CERERE ET LIBERO FRIGET VENUS: EL ALCOHOLISMO COMO PROBLEMA DE SALUD EN EL MONACATO VISIGODO*
}

\author{
POR \\ LUIS R. MENÉndez BUEYES ${ }^{1}$ \\ Universidad de Salamanca
}

\section{RESUMEN}

A lo largo del reino visigodo de Toledo se fue conformando el primer monacato hispano. Las reglas conservadas lo caracterizan como de especial dureza no siempre fácilmente soportables. Esta dureza conllevó en algunas ocasiones la aparición de adiciones como el alcoholismo crónico, duramente reprobado al entenderse como un pecado de gula.

PALABRAS CLAVE: monacato; visigodos; alcoholismo crónico; pecado de gula.

\section{SINE CERERE ET LIBERO FRIGET VENUS: ALCOHOLISM AS HEALTH CONCERN IN THE VISIGOTH MONASTICISM}

\begin{abstract}
The first Hispanic monasticism was shaped during Visigoth Kingdom of Toledo. The preserved rules characterize this as a particularly rough one, so they were not always easily affordable. This hardness implied the apparition of some addictions, such as chronic alcoholism, which was hardly reprobated as it was understood to be a greed sin.
\end{abstract}

KEY WORDS: monasticism; Visigoths; chronic alcoholism; sin of gluttony.

Cómo CITAR ESTE ARTículo / CitATION: Menéndez Bueyes, L. R. 2019. «Sine cerere et libero friget venus: el alcoholismo como problema de salud en el monacato visigodo». Hispania Sacra 71, 143: 25-38. https://doi.org/10.3989/hs.2019.002

Recibido/Received 28-11-2017

Aceptado/Accepted $\quad$ 06-02-2018

\section{INTRODUCCIÓN}

«Sine Cerere et Libero friget Venus», este proverbio latino, recogido por diversos autores antiguos, ${ }^{2}$ lo fue también, de forma especialmente significativa para el problema que tratamos aquí, por parte de Jerónimo en una de sus cartas. $^{3}$ En efecto, este pionero del monacato, a caballo entre los siglos IV y V, con su peculiar espiritualidad, cargada de

\footnotetext{
${ }^{*}$ El trabajo se enmarca dentro del Proyecto Formación y dinámica de los espacios comunales ganaderos en el noroeste de la península ibé rica medieval: paisajes e identidades sociales en perspectiva comparada (HAR2016-76094-C4-4-R), del Ministerio de Economía y Competitividad.

1 mbueyes@usal.es / ORCID iD: https://orcid.org/0000-0001-85743492. Miembro del Grupo de Investigación ATAEMHIS.

2 Minucio Félix, Oct. XXI, 2; Terencio, Eun. 732, de quien la toma Jerónimo.

3 Jerónimo, Ep. 54.9.
}

rigorismo ascético, pero de cuya realidad participa también un mundo pleno de relaciones sociales característicamente romano, ${ }^{4}$ representa un magnífico ejemplo de lo que el consumo de bebidas alcohólicas, sobre todo de vino, significó para los cristianos, especialmente para aquellos que querían abrazar una vida dedicada plenamente a la religión a través de las diversas modalidades del monacato.

El vino, uno de los componentes de la tríada mediterránea por excelencia, era un elemento esencial de la dieta greco-romana durante la Antigüedad. ${ }^{5}$ Se trataba de un producto de primera necesidad, por lo que era ampliamente cultivado y comercializado, existiendo una significativa literatura especializada sobre la viticultura. ${ }^{6}$ Las fuentes

\footnotetext{
4 Sobre Jerónimo ver ahora Williams 2006.

5 Garnsey 1999: 12; Dalby 2003: 350-352; Kron 2015: 165.

6 Kron 2015: 164-168; Donahue 2015: 254-258; Leigh 2015: 43-52.
} 
nos hablan de que su consumo, en virtud de sus diferentes calidades, estaba al alcance de todos los grupos sociales, además de la disponibilidad de otras bebidas alcohólicas, como la cerveza, tal y como las fuentes nos evidencian para puntos tan distantes y diferentes de la geografía romana como Egipto, Hispania o la Galia; llegando, según algunos estudios, a un consumo de una botella por día para los adultos y con un posible aumento del consumo a partir del siglo II d. C. ${ }^{7}$ Y en este sentido, la importancia de los banquetes cívicos, tanto privados como públicos, son una elocuente manera de ejemplificar la importancia que el consumo del vino tenía en el mundo antiguo. ${ }^{8}$

La literatura médica recoge también la importancia en este ámbito del vino. En efecto, su consumo en exceso puede producir, entre otros problemas, enfermedades sociales, pero al mismo tiempo se trata de un potente diurético en una sociedad que carecía de otros productos que cumplieran con esta misión, como el café o el té. Mientras que es considerado peligroso para los niños, mujeres y jóvenes, su valoración es positiva para los ancianos, a quienes su consumo puede beneficiar al ayudarles a calentarse y permitir una buena digestión de los alimentos, siguiendo la teoría vigente del equilibrio de los humores expuesta por Galeno. ${ }^{9}$

Esta forma de entender el consumo del vino por la literatura médica resulta sumamente ejemplificadora de la ambigüedad con la que los autores del mundo antiguo $y$, en especial, del ámbito romano, tratan la cultura del vino. Una ambigüedad que, al igual que en otros aspectos, tiene en la actitud de los cristianos su último correlato al rechazar la carne sobrante de los sacrificios paganos - al igual que los pitagóricos-, al mismo tiempo que se establece como ritual central la comida eucarística del pan y del vino; ${ }^{10}$ vino que a veces rechazan frontalmente - salvo en su uso como medicina- y que en otras ocasiones asumen como parte de la dieta normal, incluso entre los eclesiásticos.

La citada carta de Jerónimo viene a resumir el problema que el vino significó en el mundo antiguo: la lucha entre la necesidad de su consumo como parte de una dieta equilibrada, su uso como medicina y elemento esencial de los ritos eucarísticos y, al mismo tiempo, principal enemigo del rigorista cristiano.

A lo largo de diversas epístolas, Jerónimo - siempre con el apoyo de citas bíblicas y evangélicas - ${ }^{11}$ irá desarrollando la idea de que el consumo de vino, fundamentalmente por el estado de euforia que conlleva, sobre todo si se llega a la embriaguez, es reprobable en la gente de Iglesia. ${ }^{12}$ Con

7 Garnsey 1999: 118-119. Gourevitch y Demigneux 2013: 73.

8 Garnsey 1999: 131-135; Dalby 2003: 318-321.

9 Rousselle 1989: 75: Dalby 2003: 351; Wilkins 2015: 62 y 66. Ésta postura galénica sera adoptada expresamente por uno de los grandes Padres de la Iglesia como es Jerónimo (Ep. 54.9-10), quien admite el consumo de vino únicamente en caso de enfermedad - siguiendo preceptos bíblicos y evangélicos-, y para calentar a los ancianos, según las teorías galénicas, pero no para los jóvenes. En el Corpus Hipocrático son relativamente frecuentes las referencias a bebidas alcohólicas y su aplicación terapéutica: Barona Vilar 2003: 1-2.

10 Garnsey 1999: 95-98 y 143; Smith 2015: 357-364.

11 Las principales citas usadas por Jerónimo, y otros grandes Padres, son 1 Tim 3,1-7; 8-10; 1 Tim 5,23; Éx 32,6; Gén 9,21; Gén 19, 31-33; Ef. 5,18; Rom 13,12; Rom 14,21; Lc 1,15; Lc 21,34-35; Tit 1,5-9.

12 Jerónimo, Ep. 14.8; 22.8; 52.11; 54.9-10; 55.2; 69.2; 69.3; 69.8; 69.9; 78.41; 79.7; 100.5; 100.6; 107.3; 108.11; 108.21; 125.7; 127.4; 117.6-7; 132.9 . la sentencia "Sine Cerere et Libero friget Venus», de nítidas reminiscencias clásicas, plantea Jerónimo el principal problema que el consumo de alcohol tiene para un clérigo: la pérdida de control que lleva a la concupiscencia, a la lujuria. Lujuria que es uno de los principales pecados que puede cometer alguien que ha consagrado su vida a Jesucristo, pero también para cualquiera que aspire a la perfección cristiana. ${ }^{13} \mathrm{Y}$ es que si bien la depreciación del cuerpo y de la sexualidad ya se había iniciado en la época romana, especialmente desde Marco Aurelio, serán ideólogos como Jerónimo y Agustín y la institución del monacato los que elevarán por mucho tiempo hasta el máximo prestigio la virginidad y la castidad - una nueva ética sexual en definitiva- al enmarcarlas en sus importantes proyectos intelectuales. De este modo, la fornicación, la concupiscencia y la lujuria, serán la sublimación de las ofensas a Dios, materializándose en buena medida en la glotonería y en el exceso del consumo alcohólico, el pecado capital de la gula. ${ }^{14}$

Con rotunda claridad lo expresa Jerónimo dentro de uno de sus ejercicios de exégesis: «Etenim luxuria mater libidinis est, uentremque distentum cibo et uini potionibus inrigatum uoluptas genitalium sequitur, atque, ut ita dictum set, pro membrorum ordine ordo uitiorum mutandus est. Omne itaque peccatum, uerbi gratia furtum, homicidium, rapina, periurium et cetera his similia post factum paenitudinem habent, et licet inuitet lucrum tamen mordet conscientia; uoluptas sola ac libido etiam in ipso tempore paenitendi praeteritos stimulos patitur; et titillationem carnis, et incentiua peccati, ut per haec quae corrigi cupimus cogitantes rursum sit materia delinquendi». ${ }^{15}$ Vino, lujuria, placer y deshonestidades son inseparables: "vinolentia scurronum est et comissatorum, uenterque mero aestuans cito despumat in libídines. In uino luxuria, in luxuria uoluptas, in uoluptate impudicitia est». ${ }^{16}$

Esta conciencia negativa sobre el vino, y especialmente sobre su abuso, se encuentra igualmente en otros padres de la Iglesia, si bien no en todos con la misma insistencia que muestra Jerónimo. Así, Agustín, en su epistolario, habla duramente al respecto. ${ }^{17}$ El de Hipona presenta casos en los que se constatan diversos desmanes relacionados con la ebriedad: "sed quoniam istae in cimiteriis ebrietates et luxuriosa conuiuia non solum honores martyrum a carnali et imperita plebe credi solent». ${ }^{18}$

Otro autor de enorme trascendencia para el cristianismo formativo será Gregorio Magno, cuyas obras conocerán una gran difusión, por ejemplo, en la Iglesia hispana. Una de sus obras más influyentes será, precisamente, la Regla Pastoral. En ella, una vez más amparándose en las citas bíblicas y evangélicas, podemos encontrar la característica dicotomía de la Antigüedad a la hora de usar el vino: un uso válido, como medicina y antiséptico, y un uso del que hay que huir,

13 Royo Marín 1988: 324-340.

14 Le Goff y Truong 2005: 35-37; Lesniewski 2017: 86-97, y en general, Brown 1993, así como Brown 2016: 531-575 y 1015-1018. De hecho, desde Galeno, parte de las teorías médicas plantean el que la continencia sexual puede resultar favorable para la salud de los hombres: Rousselle 1989: 27, 34, 75 y 84-93.

15 Jerónimo, Ep. 55.2.

16 Ibídem 69.9.

17 Como ejemplo sirvan Agustín, Ep. 22.1.2-3; 22.1.6; 29; 35.2; 36.2.3: 36.7.14-15; 36.8.19; 55.19.35; 78.6; 93.11.48-49.

18 Agustín, Ep. 22.1.6. 
el que conlleva embriaguez y, en consecuencia, un camino a la lujuria. ${ }^{19}$

Pero, ¿significan estas abundantes menciones en la literatura cristiana que el alcohol es un problema de salud además de un problema moral? ¿Nos encontramos ante un problema de adicción, especialmente sensible cuando se trata de clérigos? El propio Agustín señala que nos encontramos ante problema extendido, además de muy evidente: «melius enim hoc uitium commemoro, quod nec occultare possunt, in quibus regnat, et, quam multi ubique sint, quis uel caecus ignorat?». ${ }^{20}$

A lo largo del presente trabajo intentaremos contestar a esta cuestión a través de la presentación de evidencias relacionadas con el monacato hispano de época visigoda en las que se puede intuir la existencia de alcoholismo crónico. Pero antes será necesario conocer el problema durante la etapa romana.

\section{EL ALCOHOLISMO EN EL MUNDO ROMANO}

No existe acuerdo sobre si en el mundo clásico tenemos evidencias claras sobre la adicción al alcohol. ${ }^{21}$ La medicina greco-romana era consciente, más allá de sus usos como medicina, de las graves consecuencias que podría conllevar el consumo excesivo de alcohol para determinados órganos: el sistema digestivo, el neurológico y, en general, para la cabeza. ${ }^{22}$ Pero fundamentalmente nos encontramos ante un uso social del abuso del alcohol, algo que, en muchas ocasiones, lejos de estar mal visto, se fomenta, incluso como moda. ${ }^{23}$ Los propios médicos distinguían entre el «alcoholismo agudo" y el "alcoholismo habitual», que nos es estrictamente un problema médico como el primero. ${ }^{24}$

Plinio el Viejo nos informa de los excesos que se cometían para poder seguir bebiendo, considerando el vino como un producto que «trastorna la mente del hombre y hace surgir la locura», hasta el punto de que "el hombre, por culpa del vino, es el único animal capaz de beber sin sed». Describe también algunos de los síntomas de los bebedores habituales, como la escasez de horas dedicadas al sueño, la palidez, párpados caídos, los ojos inyectados en sangre, las manos trémulas, pesadillas y búsqueda de un "placer sacrílego", así, como al día siguiente «olor como de cántaro de vino, que sale de la boca, y el olvido de todas las cosas y la muerte de

19 Gregorio Magno, De cura past. II.6; II.7; III.16; III.19; III.24; III.25; III.27; III.32 y III.34.

20 Agustín, Ep. 93.11.48.

21 Pese a existir ya una amplia bibliografía sobre el tema: Gourevitch 1991. Esta autora, una de las mayores especialistas en la Historia de la Medicina Antigua, considera que pudieran rastrearse algunos presuntos casos en el Corpus Hipocrático, en especial en Epidemiae 1.27.2; 27.8; $3.1 .4 ; 3.1 .5 ; 3.17 .10 ; 3.17 .16 ; 5.2 ; 5.81$ y 7.86 (Gourevitch y Demigneux 2013: 82). Pero también en Sent. II.21 y V.5.

22 André 2006: 47, 55, 293, 342-345, 516; Gourevitch y Demigneux 2013: 82-83.

23 Para J. H. D'Arms (1995: 257) las normas del arte de beber se establecerían como una forma de legitimar culturalmente la bebida entre las clases superiores. En la misma línea, Manzanero Cano et al. 2010: 257, nota 456.

${ }^{24}$ Tenemos ejemplos de estos bebedores habituales en la literatura antigua de todo tipo, desde Plauto (Curculio 77-79) hasta Agustín (Conf. 9.8), pasando por los testimonios de los papiros. Sobre esta cuestión D’Arms 1995; 315-316; Gourevitch y Demigneux 2013: 83. la memoria». ${ }^{25}$ También en Plinio nos encontramos la constatación de que en otras áreas, como Galia, Hispania y Egipto existen otras bebidas alcohólicas, como la cerveza, lo que le lleva a concluir que «en ninguna parte del mundo falta la embriaguez, pues, en efecto, tales zumos los beben puros y no los rebajan diluyéndolos como hacen con el vino». ${ }^{26}$

La literatura médica recoge diversos casos agudos, y si bien una parte de la investigación se muestra escéptica con respecto a la existencia de alcoholismo en el mundo antiguo, otros autores creen que sí pudo existir un cierto nivel de adicciones. ${ }^{27}$ En textos tan distintos como la Biblia o las obras de historiadores como Amiano Marcelino o Procopio, se recogen episodios en los que las borracheras son sancionadas moralmente, como hiciera Plinio. ${ }^{28}$ Amiano realiza numerosos comentarios al respecto que van desde el desmesurado gusto por las bebidas alcohólicas por parte de los galos hasta la crítica al gran consumo de vino en los templos públicos que acompañan a las comidas, pasando por casos concretos en los que la embriaguez ha desembocado en un final dramático, contraponiéndolos al ejemplo de la frugalidad en el comer y en el beber de los obispos cristianos. ${ }^{29}$ Pero en este sentido, tal vez las dos informaciones más significativas ofrecidas por este historiador del siglo IV son aquellas que, conteniendo valoraciones morales sobre las actitudes de los personajes, nos informan sobre dos hábitos alcohólicos distintos que acaban en justo castigo por su comportamiento.

Por una parte tenemos el caso del emperador Joviano, defensor de la religión cristiana según Amiano, que no carecía de virtudes, pero que "edax tamen et vino Venerique indulgens, quae vitia imperiali verecundia forsitan correxisset». Gula, vino y placeres del amor que empañaron su dignidad según Amiano. ${ }^{30}$

El otro caso es el de Esculidón («Quorum Scudilo destillatione iecoris pulmones vomitans interiit»), ${ }^{31}$ que viene interpretándose como una muerte por vómito de sangre a causa de un absceso de hígado, lo que podría ponerse en relación con la propia muerte de Atila tras una noche de celebraciones, ${ }^{32}$ muerte que bien pudiera ser consecuencia de una cirrosis hepática. En el año 452, tras la fiesta nupcial con Ildico, Atila muere por asfixia a consecuencia de una hemorragia nasal, posiblemente a causa de un reventón de las venas varicosas que tenía en el cuello o por una

25 Plinio el Viejo, Nat. Hist. XIV 137-148.

26 Ibídem XV 149.

27 Entre los escépticos destacan D'Arms 1995, Claryse 2001 y Dalby 2003: 123-124. Por el contrario, Gourevitch 1998 piensa que existen ciertas adicciones. En el caso del cristianismo, las conexiones entre el consumo de vino y embriaguez son, como estamos viendo, muy evidentes. Al respecto véase Lançon 1990 y Bailey 2007. En general, se considera que el alcoholismo no se convirtió en un grave problema de salud hasta el proceso de industrialización de inicios del siglo XIX: Barona Vilar 2003: 3-4.

28 Gén 9,20-27; 1 Sam 25,36-38; Tob 4,15; Prov. 23, 20-21; 23, 29-35; Sirach 31, 25-31; Jes 5, 11-12; 19, 14; 28, 7-8, muchas de ellas de uso habitual en Jerónimo o Agustín. Por su parte, Procopio, Bell. Goth. 5.3.10, critica a un general que, debido a la borrachera, perdió el autocontrol.

${ }_{29}$ Amiano Marcelino, Res Gestae 15.12.4; 22.12.6; 24.1.16; 28.8.2; 27.3.15.

30 Ibídem 25.10.15.

31 Ibídem 14.11.24.

32 Jordanes, Gética 254. 
hemorragia digestiva provocada por esas venas. ${ }^{33}$ Se trata de un síntoma que puede relacionarse con el desarrollo de una cirrosis. En efecto, los sujetos con esta patología pueden permanecer asintomáticos, sobre todo en pacientes abstinentes. Pero cuando la afección progresa surgen signos de hipertensión portal como ascitis, circulación colateral y varices esofágicas. De hecho, la aparición con mayor frecuencia de reflujo gastroesofágico, que favorece la aparición de esofagitis y el desarrollo de estenosis pépticas y úlceras del tercio inferior del esófago, es algo frecuente en los alcohólicos. Al alcoholismo se asocian igualmente la aparición de laceraciones en la unión gastroesofágica, lo que se conoce como síndrome de Mallory-Weiss. ${ }^{34}$

En cuanto a las lesiones causadas por el consumo de alcohol, la más conocida sin duda es la que se desarrolla en el hígado, cuyos síntomas son anorexia, náusea, vómito, diarrea, dolor vago en el cuadrante superior derecho, fatiga, debilidad, fiebre, ictericia, amenorrea, impotencia e infertilidad. ${ }^{35}$ Cuando el hígado se adematiza (hepatitis alcohólica) la cirrosis es establece en pocos años. Cuando esto ocurre, la función hepática disminuye de manera progresiva, interfiriendo sobre la secreción de la bilis (ictericia), la síntesis de proteínas (tendencia a la hemorragia, al edema, etc.) y el flujo sanguíneo. Esta interferencia sobre el flujo sanguíneo es la causante de las ya mencionadas y características consecuencias que causan hipertensión portal, restringiendo el flujo sanguíneo hacia el hígado, teniendo como consecuencias la aparición de ascitis, varices esofágicas y sangrado del esófago. La cirrosis hepática puede llegar a ocasionar carcinoma hepático. ${ }^{36}$

Danielle Gourevitch, en su estudio de las adicciones en el mundo grecorromano, ha estudiado dos casos en los que se puede rastrear los efectos devastadores de un excesivo consumo de vino. ${ }^{37}$ En concreto, los casos analizados son los de un joven griego de Chalkis (Eubea) y el de un pequeño esclavo de Pérgamo. En el primero, establece como posibles causas de la muerte un síndrome de Mallory-Weiss o, más probablemente, al no tratarse de un bebedor habitual, de una intoxicación etílica aguda por exceso de alcohol. El segundo caso es interpretado como una intoxicación aguda, junto con hepatitis alcohólica y encefalitis en un paciente joven insuficientemente nutrido, lo que puede desarrollarse de forma repentina y severa sin fase eufórica previa. ${ }^{38}$

En definitiva, el alcoholismo en el mundo romano presenta dos variantes desde el punto de vista de los testimonios

33 Jones 2013: 352; Gargantilla Madera 2016: 81; Damjanov 2010: 270-271.

34 Entre el 5 y el $15 \%$ de las cirrosis hepáticas alcohólicas evolucionan a un carcinoma hepatocelular. Por otro lado, un factor protector frente al alcoholismo es el déficit congénito de deshidrogenasa, habitual en las razas mongoloides. Con respecto a estos temas Gual Solé 2011 348 y 357 . El síndrome de Mallory-Weiss implica la aspiración o inhalación de vómito profuso de materia orgánica sangrienta a consecuencia del repentino desprendimiento de la membrana mucosa, lo que suele ser interpretado por los profanos en medicina como si se tratara de sangre pura (Knauer 1976: 5-8; Cáceres Anillo 2007: 136; Gourevitch y Demigneux 2013: 76; Spaete y Branch 2016: 81-87).

35 Fauci et al. 2008: 1971-1972, 1984 y 2726.

36 Biesalski y Grimm 2012: 274.

37 Esta autora cree ver claros indicios de adicción al vino, el opio y diversos medicamentos en algunos casos presentados por Galeno, incluyendo en ellos al propio emperador Marco Aurelio: Gourevitch 1998; Gourevitch y Demigneux 2013: 75-76.

38 Gourevitch 2001: 47-48; Gourevitch y Demigneux 2013: 76-80. que nos han llegado. Por una parte, su uso social, con una embriaguez tolerada, como en el caso de fiestas como las Saturnalia, convivia y victorias, así como para las elites sociales, donde el beber formaba parte de la etiqueta social. Por otra parte, una condena moral con respecto al abuso del alcohol, que se presenta como una lacra para el orden social, tanto en lo que respecta a los gobernantes que manifestaban de esta manera falta de dignidad con respecto a su cargo, como en las clases bajas, con evidencias sobre los excesos que llevaban a conductas execrables. ${ }^{39}$

\section{EL ALCOHOLISMO EN EL MONACATO VISIGODO}

Como hemos podido ver hasta el momento, aunque existen indicios sobre la adicción al alcohol en la sociedad romana, estos pueden ser discutibles y, de hecho, no existe consenso al respecto. Nuestra intención es presentar dos testimonios de época visigoda, ambos ligados al monacato, que, junto con otras evidencias, creemos que vienen a demostrar la existencia de casos de alcoholismo agudo en la Antigüedad.

La primera mención a un monasterium en Hispania de la que se tiene referencia es de Baquiario en el 410, y dentro del contexto de la cuestión priscilianista en la Gallaecia. Precisamente será esta circunstancia, así como la inestabilidad política del siglo $\mathrm{V}$, la que posiblemente no permitirá un desarrollo del monacato en la península ibérica, a consecuencia de las sospechas que los ascetas levantaban. La normalización de esta institución no comenzará a producirse hasta que se constaten, ya en el siglo VI, la llegada de influencias tan diversas como la del monaquismo galo, oriental o norteafricano. En concreto, la influencia de Casiano y del monasterio de Lerins, será decisiva, especialmente al instaurarse la tradición de las reglas a través de los ejemplos de las de Cesareo, así como de la influencia de las obras de Agustín y de las colecciones de dichos y colecciones normativas que venían de Oriente. ${ }^{40}$ En este mismo sentido, cobra especial importancia la noticia trasmitida por Ildefonso de Toledo sobre la llegada a España desde África de Donato, ${ }^{41}$ portador de una regla que, muy posiblemente, se trate en realidad de los escritos agustinianos, que ejercerán influencia sobre los textos monásticos hispanos tardíos del siglo VII, como la colección de consejos redactados por Leandro de Sevilla o las reglas elaboradas por Isidoro y Fructuoso o la Regla Común. ${ }^{42} \mathrm{Y}$ es en este contexto de originalidad y pluralidad del monacato hispano en el que aparecerá en la Lusitania un modelo monástico suburbano, tal y como se puede observar en las Vidas de los Padres de Mérida o, en el caso de Gallaecia, un muy peculiar monacato que se desarrolla en la segunda mitad del siglo VII, expresado en la Regla de san Fructuoso, en la Regla Común así como en los diversos y peculiares escritos de Valerio del Bierzo. ${ }^{43}$

\footnotetext{
39 Sobre estas cuestiones D’Arms 1995 y Gourevitch y Demigneux

40 Mundó 1957: 95-97; Díaz 2006: 11-15, 2017: 463-468.

41 Ildefonso de Toledo, De vir. ill. 3.

42 Manrique Campillo 1969; Díaz 2006: 15, 2015: 338-349, 2017 :

43 Hillgarth 1980; Chavarría 2004: 116-117; Rodríguez Castillo 2005: 57-103; Amaral 2009; Díaz 2006: 20, 2017: 473-493.
} 2013: 73-75. 469-470. 
Valerio del Bierzo da cuenta de uno de los más interesantes episodios en materia médica de los que podemos encontrar entre sus obras. En él, más allá de las continuas opiniones vertidas por el autor - y que se constituyen como algunas de las mejores muestras de las particularidades de su personalidad marcada por el trastorno esquizotípico-, ${ }^{44}$ los numerosos detalles de la historia ponen sobre la mesa un posible caso de alcoholismo crónico, una patología que debió de estar bastante extendida entre los hombres de iglesia de la época. En efecto, como podemos intuir por este y otros casos, el alcoholismo no debió de ser raro en la época tardoantigua, al menos entre aquellos que podían tener un mayor acceso al vino, como es el caso de los eclesiásticos. De hecho, la insistente reiteración con que Leandro de Sevilla habla sobre el uso moderado del vino entre los eclesiásticos, limitando su ingesta como medicina, así como la crítica a su excesivo consumo, podría estar indicando que en los conventos existían problemas de abuso de alcohol. ${ }^{45} \mathrm{La}$ conclusión de Leandro es clara: "Ebrietas enim mortale est crimen: inter homicidios, adulteriis uel fornicationibus reputatur. Sic eiicit a regno Dei uini temulentia, quemadmodum facinus aduterii uel homecidii uel aliorum criminum flagitia. [...] Vide quam sit execranda ebrietas ut etiam a regno Dei suos amatores eiciat».

Podemos encontrar algunos indicios de alcoholismo entre eclesiásticos de época visigoda. Así, la enfermedad de hidropesía (ascitis) es mencionada en la biografía de san Millán, padeciéndola el monje Armentario y, tal vez, el propio santo. ${ }^{46}$ Por otra parte, Braulio de Zaragoza, en una dura réplica al presbítero Tajón en el 631 le acusa de gustarle más el vino que las palabras, lo que se constituye en una clara acusación de alcoholismo, si bien puede ser una parte de su retórica en la contestación. ${ }^{47}$ En este sentido, una posible velada alusión al alcoholismo la podemos encontrar

44 Díez Manrique 2011.

45 Regula Leandri XIX; igualmente la Regla Fructuosiana plantea la existencia de monjes dados a la embriaguez en el monasterio, a los que se les aplicarán penas durísimas, que van desde amonestaciones orales a castigos corporales, la excomunión temporal, encarcelamiento y dieta de pan de cebada y agua, detalle este de especial simbolismo (Reg. Fruct. XV); algo parecido ocurre con Isidoro (Reg. Isid. XVII). Al respecto, Domínguez del Val 1981: 265 y 511; Menéndez Bueyes 2013: 44. El propio Valerio (De genere monachorum 4), critica a los falsos monjes, que no son capaces de contener su "voracidad en el comer y en el beber»; también en otro lugar (Epitameron de quibusdam ad monitionibus vel rogationibus 2 y 13), advierte sobre la necesidad de reducir la cantidad de comida, absteniéndose especialmente de la carne y recomendando la moderación en el vino. Se siguen así las prescripciones de la mayor parte de las reglas monásticas visigodas. En el monacato oriental también hay cierta disparidad entre los que prohíban el consumo de vino, los que lo permitían con moderación o aquellos que los destinaban a un uso medicinal o para los ancianos (Rousselle 1989: 194 y 197).

${ }^{46}$ La causa de la ascitis frecuentemente es una cirrosis hepática (e $75 \%$ de los casos en la clínica actual), con insuficiencia renal que conduce al síndrome hepatorrenal e, incluso, a insuficiencia cardiaca congestiva que puede provocar la muerte súbita por fibrilación ventricular, con una mortalidad muy alta cercana al 90 \% de los casos (Cáceres Anillo 2007: 136-138; Laso Guzmán 2010: 139-140; Rozman 2010: 77-78; Damjanov 2010: 269-271; Gual Solé 2011: 357). La ascitis fue descrita por la literatura médica de la antigüedad, desde el Corpus Hipocrático hasta las Etimologías, pasando por Galeno y Alejandro de Tralles, poniéndose en relación su diagnóstico diferencial con la malaria (Menéndez Bueyes 2013: 35-36). También el emperador bizantino Heraclio murió a causa de ella, según la Crónica Mozárabe de 754, 18.

47 Braulio de Zaragoza, Ep. 4. en Ildefonso de Toledo cuando se refiere al diácono Justo: «Rursum cum Helladio, episcopo sedis eius, lustus diaconus fastu superbiae insultaret, post mortem quidem sui pontificis uixit episcopus et ipse; sed tabefactus et in reprobrum uersus sensum, ob intemperantiam morum a ministris altaris sui dormiens strangulatus laqueo expirauit». ${ }^{48} \mathrm{El}$ pecado de intemperancia se define como «el extremo opuesto a la virtud de la sobriedad", "formado por el apetito desordenado de la comida y bebida, también llamado gula. Consiste primariamente en un apetito sensitivo, el cual se convierte en intemperancia, en sentido propio, cuando es permitido o querido culpablemente por la voluntad", y si bien, se considera un pecado leve en condiciones normales, puede pasar a serlo grave «cuando los excesos constituyen un peligro grave e inmediato para la salud, suponen un derroche desenfrenado o llevan consigo una entrega total del hombre al placer sensual de la comida o la bebida», en definitiva, «la embriaguez, causada por el exceso de bebida, constituye una clase de intemperancia», siendo un pecado grave cuando se trata de embriaguez completa, que priva del uso de la razón, o siendo incompleta cuando se hace habitual. ${ }^{49}$

No se trata, obviamente, únicamente de un problema de los monjes hispanos. Beda nos da a conocer el caso de cierto monje, hábil artesano: «novi autem ipse fratrem quem utinam non nossem, cuius etiam nomen si hoc aliquid prodesset dicere possem, positum in monasterio nobili, sed ipsum ignobiliter viventem. Corripiebatur quidem sedulo a fratibus ac maioribus loci, atque ad castigatiorem vitam converti ammonebatur. Et quamvis eos audire noluisset, tolerabatur tamen ab eis longanimiter, ob necessitatem operum ipsius exteriorum: erat enim fabrili arte singularis. Serviebat autem multum ebrietati et ceteris vitae remissioris incelebris». ${ }^{50}$ Un caso de alcoholismo crónico que acabará con una enfermedad - posiblemente relacionada con ese alcoholismo- que le conduce a la muerte finalmente. Que el problema estaba extendido, lo evidencia igualmente el que el Concilio de Agde de 506 prohíbe a los clérigos la ebriedad, "por ser la causa y alimento de todos los vicios», castigándose con penas de excomunión temporal y castigos corporales. ${ }^{51}$

Como señala A Gual: «La capacidad adictiva del alcohol se halla en la base de la adicción al alcohol, y esa es una obviedad a menudo despreciada en las culturas vitivinícolas, en las que se tiende a minimizar la importancia del alcohol en la génesis de la dependencia alcohólica y en cambio se enfatizan los factores de vulnerabilidad individual». ${ }^{52}$ $\mathrm{Y}$ añade este investigador que este último factor, la vulnerabilidad individual (como son los antecedentes paternos de alcoholismo), es importante para el riesgo de que una persona desarrolle síndrome de dependencia alcohólica, pero el mismo también se halla relacionado con el nivel de exposición al alcohol, sobre el que, a su vez, presentan una gran

48 Ildefonso de Toledo, De vill. illust., Praefatio 36-40.

49 Mausbach y Ermecke 1974: 194-196. Ya Isidoro (Reg. Isid. IX) escribió sobre su relación con la embriaguez, como veremos más adelante.

50 Beda, Hist. Eccle. Gent. Angl. V 14.1.

51 Curado 2004: 79. En general, sobre la disciplina eremítica en el monacato hispano, ver Orlandis 1964, y en particular para el visigodo Cavero Domínguez 2017.

52 Gual Solé 2011: 348. 
influencia los factores sociales, culturales y económicos que determinan la accesibilidad al alcohol. ${ }^{53}$

En este sentido, es evidente en primer lugar, que los monjes disponen de accesibilidad al vino y otras bebidas alcohólicas, como la sidra, debido a las existencias que en todo monasterio se encuentran, tanto para su utilización como bebida, como para sus usos medicinales y litúrgicos, tal y como nuestras fuentes evidencian en numerosas ocasiones, tanto de forma directa como indirecta al hablarnos del cultivo de viñas. ${ }^{54} \mathrm{Y}$ en segundo lugar, la vulnerabilidad individual de los monjes es algo que se puede constatar en los numerosos episodios que documentan desequilibrios mentales en la literatura monástica y eclesiástica, especialmente trastornos de la personalidad, depresiones y estrés..$^{55}$ Una vulnerabilidad que las duras condiciones de la vida monástica acentúa, propiciando en ocasiones desvaríos que son consecuencia de una inadecuada apropiación psíquica del hecho religioso, de una perturbación interna fruto de disposiciones congénitas, de las fases de evolución del individuo y de su historia personal. ${ }^{56} \mathrm{El}$ propio Valerio del Bierzo, con sus extraños comportamientos, es un magnífico ejemplo de ello, o el de aquellos monjes que no pueden soportar más la presión y se ven obligados a huir. ${ }^{57}$ Que nos encontramos ante un problema recurrente lo demuestra el hecho de que en diversos concilios se legisló con respecto a los clérigos desertores y fugitivos. ${ }^{58}$ También en este sentido es muy significativa para nuestros propósitos la Regla Fructuosiana, que muestra una austeridad y disciplina en la vida cotidiana de los monjes que hace de su profesión monástica algo a duras penas tolerable, siendo precisamente esta dureza

53 Ídem.

54 Por ejemplo como señala Reg. Isid. XXI.

55 A manera de ejemplo se pueden ver diferentes casos hispanos en Menéndez Bueyes 2013: 45-47.

56 Pöll 1969: 189-192, 336-337 y 448-449. Isidoro (Sent. III.19.4) habla del peso del siervo de Dios, que nunca tiene seguridad de que "cuanto hace consiga el premio de la virtud», y "por esto mismo se vuelve triste y afligido».

57 Díez Manrique 2011: 35-38. Ya Jerónimo nos comenta diver sos casos en los que los monjes no soportan la presión de vivir en un espacio reducido, en soledad y en régimen de abstinencia, enfermando al fallarles la cerebro sanitatem (Jerónimo, Ep. 130.17), cayendo en la melancolía, por lo que «Hippocrates magis fomentis quam nostris monitis indigent» (Jerónimo, Ep. 125.16); sobre este tema ver Ferngren 2009: 57-58. Este parece ser el caso - un ataque de ansiedad- contado por Valerio del Bierzo (Replicatio semonum a prima conversione 22). La Regla Común menciona monjes que quieren abandonar su propio monasterio, posiblemente a causa de un episodio depresivo (Reg. Com. XIII). Juan Casiano informa de problemas similares en el monacato del sur de la Galia en el siglo V (Inst. X.1-2; X.6; X.25): es el tedium uitae (acedia) de los monjes, considerado como un pecado de negligencia, que se materializa en una de sus expresiones más evidentes en el horror loci que provoca la celda (Curado 2004: 75; Lesniewski 2017: 129-136). Sobre la no reversibilidad de la profesión y sus implicaciones Díaz 1987: 149-153. En este sentido, el consumo de alcohol se relaciona con el desencadenamiento de crisis de angustia, trastornos de crisis de pánico de forma aislada y desarrollo de fobia social: Ponce Alfaro et al. 2003: 249.

58 Así en el // Concilio de Braga de 572, en su canon XXXIV; el /I Concilio de Sevilla de 619, canon III y el XIII Concilio de Toledo, de 683, que en su canon XI, extiende las sanciones a los monjes fugitivos o vagabundos: "Placuit ergo subdiaconum uel quemliuet clericum seu etiam monachum fugientem uaguumque suscipat, non ad fugam suadeat, non fugae latibulum praebat» (Vives 1963: 96, 165 y 429-430). En Juan Casiano (Inst. X.6) aparecen unos monjes itinerantes como consecuencia de la acedia, así como la figura de los monjes desertores (Inst. VII.910). Vid. Cavero Domínguez 2017: 8-9. su rasgo más definitorio. ${ }^{59}$ Ser monje es una forma de vida integral, incluyendo lo que podríamos llamar el mundo laboral del propio monje, el entorno en el que desarrolla sus actividades diarias, y que es uno de los lugares de mayor conflictividad para los alcohólicos. Aquí, además de ser uno de los principales factores desencadenantes de la adicción, puede darse rienda suelta a los sentimientos de sensación de fracaso, ansiedad, fatiga y estrés, insatisfacción, desmotivación, desesperación, desequilibrios físicos y psíquicos, conflictividad y agresividad..$^{60}$

$Y$ en estas duras condiciones de vida, el monje, pese a todo, se ve expuesto a las pasiones más bajas, a la lujuria y la concupiscencia que los Padres de la Iglesia tanto criticaron. En las reglas monásticas visigodas aparecen mencionadas en diversas ocasiones las poluciones nocturnas de los monjes. ${ }^{61}$ Celio Aureliano, médico que transmite los escritos de Sorano, señala con respecto a las emisiones nocturnas, que no se trata de una enfermedad, sino de una consecuencia de lo que se ve durante el sueño (fantasía), siendo consecuencia de un deseo sexual constante e ininterrumpido, o de la continencia. Pero, en cualquier caso, se relacionan con «una historia diurna y consciente que comporta a la vez deseo e insatisfacción». ${ }^{62}$

En efecto, las fuentes que nos aproximan a las experiencias monásticas en los desiertos orientales son ricas en datos que evidencian los problemas de continencia de los solitarios, de los monjes del desierto (relaciones sexuales con niños y con mujeres de las aldeas cercanas). Monjes acosados por el deseo sexual, por las obsesiones, por las representaciones mentales y sus manifestaciones psíquicas, como son las erecciones y eyaculaciones involuntarias. Obsesiones que únicamente pueden combatir mediante la privación alimentaria, mediante el ayuno y la abstención de ciertos alimentos como la carne y el vino. ${ }^{63}$ De ahí la permanente obsesión por el pecado de la gula, del exceso de la comida y de la bebida, que aparece constantemente criticado, y también en el ámbito del monacato visigodo. ${ }^{64}$ Isidoro los expresa claramente al hablar de las virtudes de los monjes: "Gulae concupiscentiae deprimat et abstinentiae uirtutibus semetipsum pro studio dominandarum libidinum affligat. ${ }^{65}$ Para añadir más adelante que: Non erit usque ad satietatem reficiendum corpus, ne forte intereat animus,

59 Gregoire 1967; Díaz 2006: 21-22, 2015: 342-344.

60 Benítez Hernández y León Fuentes 2003: 146-147.

61 Reg. Isid. XIII; XVII; XXII; Reg. Fruct. II. Así como en Isidoro, Sent. III.6.14. Problema recurrente en el monacato, como evidencia, por ejemplo, Juan Casiano (Inst. II.12; III.5; VI.10)

62 Rousselle 1989: 82-83, quien señala que esta idea se encuentra también en Galeno.

63 Ibídem 161, 177, 179-182. Sin embargo, como señala esta autora, pese a la caída en el pecado, estas faltas no suelen conllevar la salida de la vida religiosa. Un ejemplo de deseo sexual reprimido en un monje lo encontramos en Juan Casiano (Inst. XII.20), así como de la relación entre la fornicación y la gula (Inst. VI.1).

${ }_{64}$ Regula Leandri XIII; XXIV; Reg. Isid. III; IX; XI; XVII; Reg. Fruct. III; $\mathrm{XV}$; XVII; XIX; Reg. Com. XIX (que desaconseja el consumo de vino incluso entre los enfermos); Isidoro, Sent. II.43.4; II.43.1-8. También Ildenfonso de Toledo, De cognitione baptismi I.142 y De itinere deserti II.22. Igualmente Eutropio, en una carta al obispo Pedro de Arcávica (De octo vitiis), reflexiona sobre el vicio de la glotonería que lleva a la embriaguez, tomando una vez más como fuente a Juan Casiano (Inst. V). Agradezco esta referencia al prof. P. C. Díaz.

65 Reg. Isid. III. 
nam ex plenitudine uentris cito excitatur luxuria carnis. Qui autem appetitum edacitatis reprimit sine dubio lasciuie motus restringit. Tanta cum discretione reficiendum est corpus ut nec nimis abstinentia debilitetur, nec superflua edacitate ad lasciuiam moueatur. In utroque ergo temperantia adhibenda est». ${ }^{66}$

En consecuencia, los ayunos y abstinencias, muy recomendables, o directamente obligatorios en determinados momentos, sobre todo en lo referido a los productos «prestigiosos» como la carne, el vino y el aceite, pueden llevar a excesos en el rigorismo alimenticio, tal y como puede observarse, por ejemplo, en Juan Casiano, llegando al borde de la desnutrición. Sin embargo, todo será inútil, puesto que, incluso, el propio Casiano señala que las fantasías sexuales y el deseo aumentan en la primera fase de desnutrición, tal y como se ha podido comprobar en los estudios del hambre. ${ }^{67}$

De ahí también el cuidado con que muchas reglas monásticas tratan de minimizar el contacto físico de los monjes y entre los monjes. Los Preceptos de Pacomio o las reglas de los monjes del sur de la Galia, que conocemos por Juan Casiano, ${ }^{68}$ reprimen estos contactos, por lo que "la única manifestación genital evidente era para estos hombres la emisión de esperma durante el sueño».69

Es en este ambiente en el que, independientemente de otras circunstancias individuales, podemos encontrar descritas en nuestras fuentes diversas patologías que, por entero o parcialmente, son consecuencia, directa o indirectamente, de estas duras condiciones de vida que tienen los monjes de la tardoantigüedad. Entre estas patologías encontramos manifestaciones de alcoholismo crónico, una adicción en definitiva, y algunas de sus consecuencias, como son los trastornos mentales. Isidoro, una vez más al tratar de los problemas derivados de la gula, es consciente ya de la relación entre trastornos mentales y consumo excesivo de alcohol: "Esca crapulam, potus ebrietatem generat. Ebrietas autem perturbationem gignit mentis, furorem cordis, flammam libidinis, añadiendo a continuación que ebrietas ita mentem alienat, ut ubi sit nesciat. Unde etiam et malum non sentitur quod per ebrietatem committitur». ${ }^{70}$

El primer caso de alcoholismo crónico es descrito por una de nuestras más importantes fuentes del período, las Vitas Sanctorum Patrum Emeretensium, ${ }^{71}$ muy rica en información sobre aspectos médicos. ${ }^{72} \mathrm{El}$ caso se produce en el monasterio de Cauliana, próximo a la ciudad de Mérida. En él, encontramos a un monje inclinado «desmesuradamente» a la gula y la embriaguez. Consecuencia de esta actitud, son comportamientos en los que era frecuente el robo, por lo que el abad le amonestaba verbalmente, sin resultado alguno, por lo que se procedió a intensificar la corrección mediante castigos físicos, ayunos y encierro. Como tampoco esto funcionó, casi se le dejó por imposible. Como caracterización de este comportamiento depra-

\footnotetext{
66 Reg. Isid. IX.

67 Juan Casiano, Col. XXI.35; XXII. 2-3: Rousselle 1989: 205 y 207-208.

68 Juan Casiano, Inst. II.15; IV.16. Estas normas están igualmente presentes en las reglas hispanas.

69 Rousselle 1989: 184.

70 Isid. Sent. II.43.1-2.

71 VSPE II.

72 Bien estudiados por B. Curado (2004: 69-103), quien da a conocer inicialmente este caso de alcoholismo.
}

vado, las Vitas nos informan de que el monje «ille uidelicet preceptum claustra reserata repperiens opulentissimi, ut fertur, monasterii cellaria clamo peri penetrabat, custodibus tamen eminus circunquaque obsitus callida dissimulatione cernentibus, ignorante illo, ac prestolantibus quidnam agerer, queque dulcia aut Suabia hesu potuque repperisset eousque passin uorabat bibebatque, quousque mente perdita uix ambulare ualebat». Este comportamiento nefando se refrenda con otro hecho de especial gravedad: «Post hec fercula diuersa furtim subripiens etiam uasa uinaria que husitato nomine gillones aut flascones appellantur, auferebat et in ortum contiguum monasterii inter arbusta frondosa aut arundineta condensa in loco abditissimo occulebat».

Robo de viandas y vino, pero sobre todo, consumo de comida a escondidas. Este último hecho, el comer furtivamente, fuera de la mesa común, es castigado con severísimas penas por las reglas monásticas visigodas, penas que incluyen desde la excomunión hasta los azotes. ${ }^{73}$

Estos desórdenes alimentarios, que incluían permanente ansia por comer y beber, provocaban al monje embotamiento y somnolencia que llevaban a que se quedara dormido en el suelo de la huerta. La reiteración en estos comportamientos llevó a que unos niños acabarán recriminándole su comportamiento, lo que generó un sentimiento de vergüenza y de culpa en el monje. De este arrepentimiento parece deducirse que el monje cesó en su actitud $y$, en consecuencia, en la ingesta de alcohol. Pero poco después, le sobrevino una enfermedad repentina que le provocó una fiebre muy alta, falleciendo al tercer día. La historia se cierra con un detalle curioso que redondea el arrepentimiento del pecador: tras más de quince años, una inundación del ría Anas - de donde deducimos que el monasterio se encontraba en su ribera- anegó el monasterio y su cementerio y permitió descubrir la tumba del monje que se encontraba "ipse uero integer et incorruptus reppertus est, ac si ora eadem fuisset humatus, ut nec uestimenta eius nec capilli ex aliqua parte cernerentur fuisse corrupti».

La conjunción de factores presentados en el texto son lo suficientemente expresivos para permitir un diagnóstico de alcoholismo crónico que deriva en un episodio de Delirium Tremens. Los síntomas más graves de la alcoholemia se producen a partir de una ingesta de $300-400 \mathrm{mg} / 100 \mathrm{ml}$, con deterioro de las funciones intelectuales y físicas, sentimiento de euforia, dificultad para andar y hablar, sentimientos de confusión y somnolencia. Entre 500-600 mg / $100 \mathrm{ml}$, aparece sopor, sueño profundo, disminución de la sensibilidad, anestesia, ausencia de percepción, confusión y coma. A partir de aquí, se puede presentar insuficiencia respiratoria y muerte. ${ }^{74}$

En el caso de las Vitas nos encontramos ante un cuadro confusional agudo (Delirium Tremens) que es secundario

73 Así, Isidoro señala que «nullum esus furtiua contaminatio polluat, aut inpudens uel priuatus extra communem mensam adpetitus. Excammunicationis sententiae subiacebit qui uel occulte uel extra ordinariam mensam aliquid degustauerit» (Reg. Isid. IX). Isidoro incluye esta falta como muy grave, a la misma altura que la embriaguez, o los tratos sensuales con niños, mujeres u otros monjes (Reg. Isid. XVII). En la dura Regla Fructuosiana los monjes dados a comilonas y bebidas furtivas también son castigados con azotes, larga reclusión, y raciones de pan y agua (Reg. Fruct. XIV). Ya en Juan Casiano (Inst. IV.16-17) aparece esta prohibición de comer a escondidas, siendo necesario que coman juntos.

74 Gual Solé 2011: 355, Tabla 24-10. 
a la privación del consumo de alcohol. Suele aparecer en casos de dependencia de alcohol en bebedores crónicos entre cuatro y doce horas tras la última ingesta, aunque - pese a su variabilidad- normalmente acontece entre los dos y cuatro días, tratándose, por lo tanto, de una manifestación grave del síndrome de abstinencia. ${ }^{75} \mathrm{El}$ motivo del cese de la ingesta puede ser muy variado, como el malestar físico, una patología que impida el consumo o la adquisición del alcohol, la presión social (como parece ser en caso de este monje) o familiar, así como cualquier causa que impida el consumo. En cuanto a su curso, transcurre de tres a diez días, a partir de los cuales se reduce notablemente, aunque sin tratamiento solía contar con tasas de mortalidad de un $30 \%$ hace medio siglo, siendo su principal causa la hipertermia, las arritmias cardíacas, las complicaciones de las crisis de abstinencia o los trastornos médicos concomitantes. Se caracteriza por la obnubilación de la conciencia (en grado variable), perturbación de la orientación, paranoia, ilusiones y alucinaciones - sobre todo visuales-, distracción y estado hiperactivo con temblores, con sudor, y labilidad emocional. ${ }^{76}$ La edad avanzada, la desnutrición y la asociación con diversas enfermedades comprometen la entidad e, incluso, pueden ser factores que favorezcan su aparición, agravan la entidad y lo alargan, siendo, además, progresivamente peores en episodios repetidos; en especial son factores de riesgo las anormalidades de electrolitos y ácidos base, la infección concomitante y un trauma reciente. Entre las enfermedades asociadas las más frecuentes son la neumonía y otras sepsis, las hemorragias digestivas, enfermedades del hígado a causa del alcohol, enfermedades coronarias, anemia e hipokalemia, pudiendo correlacionarse con la depresión mayor en un $70 \%$ de los casos. También existe una predisposición genética (mutación del gen cholecystokinin, codificación del receptor opioide mu). ${ }^{77}$

En el Delirium Tremens son típicas las ilusiones y alucinaciones zoópsicas y micrópsicas (espontáneas o provocadas), siendo muy común la agitación psicomotriz (temblores, agitación), taquicardia, pupilas dilatadas, sudoración profusa y fiebre, con estados emocionales variables entre la ira, la irritabilidad, la euforia, la ansiedad o el pánico. Las alucinaciones visuales o auditivas pueden aparecer entre 24 y 48 horas tras el cese de la ingesta y suelen desaparecer en pocos días. ${ }^{78} \mathrm{Su}$ sintomatología pasa por tres fases. ${ }^{79}$ En la

75 El primer episodio de Delirium Tremens suele producirse entre cinco y quince años tras establecerse el hábito persistente de beber alcohol (Ochoa Mangado et al. 2009: 30), presentándose entre el 5 y el $20 \%$ de los alcohólicos sujetos a desintoxicación (Ferguson et al. 1996: 410).

76 Ferguson et al. 1996; Saunders y Janca 2000; Martínez Moneo et al. 2005; Cáceres Anillo 2007: 141; Ochoa Mangado et al. 2009; Schuckit 2014.

77 Saunders y Janca 2000: 629-630; Cáceres Anillo 2007: 145.

78 Laso Guzmán 2009: 473-476; Gual Solé 2011: 355; Casas y Guardia 2002: 210; Ochoa Mangado et al. 2009: 30.

79 Martínez Moneo et al. 2005. Pablo Diácono (Hist. Lang. IV.37) cuenta la historia de uno de sus antepasados, Lopiquis, que realizó un largo viaje a Italia, poniéndose en marcha con escasa comida (pan), quedándose sin nada tras varios días de marcha a través de las montañas desiertas ("cum per aliquot diez per montium solitudines hoc modo pergerent, panis eidem viatori, quem exiguum habuerat, omnino defecit»). En esta marcha lo significativo es que Lopiquis es guiado por un lobo. Según el texto, tras quedarse sin alimento, intenta matar al cánido que huye. Desesperado por la falta de alimento, debilitado, se arrojó al suelo y se quedó dormido y teniendo un sueño en el que «viditque quendam primera (entre 24-48 horas), se produce temblor de manos, inquietud, ansiedad, insomnio, náuseas, sudoración intensa y aumento de la frecuencia cardiaca y de la presión arterial. La segunda fase (a partir de las 24 horas) se caracteriza por la intensificación de los síntomas de la primera, que conlleva dificultades para realizar movimientos y para andar, pudiendo aparecer ahora crisis comiciales. La tercera fase es propiamente la que se corresponde con el Delirium Tremens (a partir de las 72 horas más frecuentemente), siendo característico de la misma la aparición de las alucinaciones visuales, que suelen ser muy vívidas, lo que repercute intensamente a nivel afectivo, de forma angustiosa para el paciente, al mismo tiempo que se produce una evidente agitación psicomotriz grave. Simultáneamente hay síntomas adrenérgicos importantes, con obnubilación, desorientación y confusión. También en esta fase pueden producirse delirios de tipo ocupacional. El conjunto de síntomas suele empeorar ostensiblemente a lo largo de las horas nocturnas.

Nuestro monje cumple con una buena parte de esta sintomatología: ingesta descontrolada y reiterada de alcohol, trastornos del comportamiento y patología infecciosa ("sed de presenti in eodem loco dolore percutiens ui febrium extuare fecit»), posiblemente una neumonía como consecuencia de quedarse dormido repetidamente en la huerta cercana a la humedad del río, ${ }^{80}$ así como un cese de la ingesta de alcohol; todo lo cual le conduce a la muerte. Una muerte precedida de un delirio típicamente ocupacional, teniendo en cuenta que se trata de un monje y que su vida viene marcada por la existencia de entidades espirituales y de santos. ${ }^{81}$ Finalmente, el hecho milagroso de la conservación del cadáver tras años del deceso es interpretado por Blas Curado como un proceso de conservación natural por adipocera que puede afectar a los cuerpos de los obesos y de los alcohólicos por degeneración grasa. ${ }^{82}$

El segundo caso es protagonizado por el presbítero Justo. ${ }^{83}$ En el relato se entremezclan las manías de Valerio y los topos literarios, pero también datos significativos para un diagnóstico de alcoholismo. Valerio comienza esta historia con una fulminante caracterización del personaje: «elegit namque nequissimum false nuncupationis nomine lustum»; en efecto, "un tipo malvado»: "forma exigue pusillitatis tantillum, ac teterrime uisionis colore barbarice nationis Ethiopum; extrinsecus enim picea cute furuo sordens obtutu, in cordis uero arcana nigrior existit penitus coruo; corpore quidem exiguus, sed criminum facinoribus copiosus».

virum in somnis talia sibi verba dicentem: "Surge! Quid dormis? Arripe viam in hanc partem contra quam pedes tenes; illac etenim est Italia, ad quam tendis"». A estas alturas Lopiquis ya había comprendido que el lobo había sido enviado por el cielo («diuinitus datum») para indicarle el camino y que el sueño completó esa misión de encaminarle hacia Italia. La historia se viene interpretando como un tipo de episodio muy del gusto de los historiadores tardíos en los que un animal tiene protagonismo (Jordanes, Gética 24; Procopio, Bell. Goth. IV.5.7-9; Gregorio, Hist. IV 44; Pablo Diácono, Hist. Lang. I.26), tal y como señala Herrera Roldán 2006: 156. Pero no podemos dejar de anotar-aparte de los efectos del hambre- ciertas concomitancias con algunos de los síntomas del alcoholismo: un período de abstinencia debido a un viaje que provoca malestar físico, visiones de animales y adormilamiento con ensoñaciones.

80 Máxime dentro de un período de temperaturas posiblemente más bajas que las actuales: Büntgen et al. 2016; Harper 2017.

81 Curado 2004: 88-89 y 93-94.

82 Ibídem: 99. Sobre este proceso Reverte Comas 1991: 836.

83 Ordo querimonie prefati discriminis 13-16. 
Este curioso pasaje asocia barbarie-color/negro-demonio. Como señala R. Frighetto, la relación entre etíopes y el demonio aparece también en otras fuentes hispanas así como en otros relatos del propio Valerio. ${ }^{84}$ Nos encontraríamos, en definitiva, ante un lugar común de carácter literario, donde Valerio retoma tanto la tradición de las Vitas de Mérida como las informaciones geográficas sobre los etíopes ofrecidas por Isidoro. ${ }^{85}$

Continúa Valerio describiéndonos los, para él, aberrantes y escandalosos comportamientos de Justo, a quien caracteriza por "el atrevimiento de sus innumerables locuras", censurando la celebración de fiestas acompañadas de música, "cantando una y otra vez con ritmos pegadizos sus canciones lascivas», lo que, posiblemente, esté haciendo relación, si hacemos caso de la posibilidad de que nos encontremos ante un personaje extranjero, a tradiciones étnicas extrañas para Valerio.

La caracterización del personaje es inmisericorde: «in tanta exarsit frenetice insaniae dementie truculentus atque inexplicabile ebrietatis temulentie inretitus, ut nec etiam nocturnis temporibus me permitteret ese quietum».

Los incidentes se suceden de forma constante: "pro caritatis consolationis mici furibundus intulit iurgium atrocitatis, et nobis in caritate conuescentibus, ille superbie uesanie sue atque ebrietate uexatus, uelut canis inruens, rabidus super nefanda conuicia frendens stridore dentium, spumansque ore lymphatico baccabundus, propriis me lacerare manibus nitebatur». Y esta situación, incluso, se ve agravada, pues «ibique me grauissimis iniuriis inrite confusum nisi fratrum intercessione fuissem ereptus, ferro me in conspectu multorum rabiens iugulare conabatur».

Borracheras repetidas (ebrietatis), que acaban desencadenando episodios de violencia extrema. Y Valerio, sorprendido por los repentinos cambios en el comportamiento

84 Como en Vitas Sanctorum Patrum Emeretensium IV.9.20-26 (a partir de ahora VSPE); Valerio Ordo querimonie prefati discriminis 2 y Replicatio sermonum a prima conversione 5 . El color negro, destacado en todo el pasaje reseñado, presenta, en definitiva, una tradición antigua en el mundo romano, usando el término «etíope» de forma peyorativa para referirse a las personas de piel negra o cetrina; nos encontramos, en definitiva, ante un tópico de los escritores cristianos para referirse a la maldad espiritual (Díaz y Díaz 2006: 261). Sin embargo, el color negro no siempre presenta connotaciones negativas, como ocurre en Isidoro (Sent. III.43.5).

${ }^{85}$ Etym. XIV, 5, 14. Con respecto a estas cuestiones, Frighetto 2006 65 , notas 205-206. Ahora bien, aunque poco frecuente, la presencia de elementos foráneos en el Noroeste peninsular durante el período tardoantiguo, tampoco es inverosímil, dada la vitalidad - hasta bien entrado el siglo VII- del comercio atlántico que pasaba por Vigo como puerto intermedio, y que unía el comercio procedente del Mediterráneo oriental, norte de África y sur peninsular con las Islas Británicas y la Galia atlántica (Fernández Fernández 2014). De hecho, y aunque hemos de ser cautos hasta que sea confirmado por análisis de ADN, el esqueleto de una mujer, de una edad estimada en torno a los 35 años, con una talla sobre los $145-150 \mathrm{~cm}$, encontrado en La Coruña en estratos datados en los siglos III-IV, ha sido caracterizado como el de una joven que pudiera tener un "origen norteafricano» por sus caracteres antropológicos (Grandal-D’Anglade et al. 2015: 50 y 54). Hemos de tener en cuenta que dentro del Imperio romano existió, incluso hasta momentos tardíos, una gran movilidad de personas, como se evidencia, por ejemplo, claramente en el caso de las Islas Británicas, donde se puede documentar la presencia de población de diversos ámbitos mediterráneos (Eckardt et al. 2014). El mantenimiento de la ruta comercial atlántica hasta momentos muy tardíos podría justificar sobradamente la existencia de población foránea en diversos puntos de este itinerario. de Justo, documenta como este se tranquiliza repentinamente de su «loco ensañamiento», cambiando "el sentido de su locura», y poniéndose a bailar "en modos propios de la obscena lujuria del teatro», de un "modo lascivo», con "pasos insinuantes», acompañándose de una «vergonzosa cantinela unas canciones temibles por su maldad y desvergüenza», " "así ejercía la lujuria de una peste diabólica».

Finalmente, la situación de Justo no presenta buen pronóstico, mostrando una serie de síntomas que son de lo más significativos: "Sic quippe exestuens mersus uino, temulentia sepultus et ebrius patiebatur sitim et esuriem uomens. Qui somno deditus desidiosoque torpore obuolutus non erat inter crebro psallentibus ymnis Dei ducentibus noctes».

Sin duda podemos encontrarnos únicamente ante un relato literario. De hecho, existe un cierto parecido entre algunos elementos de este relato con los recogidos en otras fuentes ${ }^{87}$ Pero ello no nos aleja de la existencia de una serie de comportamientos, recogidos por su excentricidad y mal ejemplo, y que se aproximan netamente a un diagnóstico de alcoholismo. $Y$ es que un consumo regular que exceda los $40 \mathrm{~g} /$ día (para los hombres) y los $24 \mathrm{~g} /$ día (para las mujeres) de alcohol, aumenta de manera significativa el riesgo de padecer problemas médicos y psicosociales relacionados con el alcohol. ${ }^{88}$

Los principales síndromes agudos relacionados con el alcoholismo son neuropsiquiátricos (convulsiones, debilidad muscular aguda, trastornos del nivel o del contenido de la conciencia, alucinaciones); ${ }^{89}$ digestivos (dolor abdominal, hemorragia digestiva); febriles (relacionados fundamentalmente con los procesos infecciosos) y cardiológicos. ${ }^{90}$ La clínica actual muestra, desde el punto de vista de la

86 El canon XXIII del III Concilio de Toledo de 589 prohibía los bailes y los cantos en las fiestas natalicias de los santos: «ut populi qui debent officia divina adtendere saltationibus et turpibus invigilent canticis» (Vives 1963: 133). La ingesta de etanol genera, al principio, en una fase conocida como fase de exaltación, locuacidad que progresa a pérdida de inhibiciones, euforia, expresión fácil de sentimientos, sensación de seguridad y fuerza, así como alteraciones de la conducta. Por otra parte, la alucinosis alcohólica cosiste en un cuadro de alucinaciones auditivas vívidas, durante, por lo menos, una semana de duración, que puede acontecer a los pocos días de la reducción o interrupción del consumo de alcohol, o, por el contrario, al aumentar el consumo durante varios días. Puede presentarse teniendo las funciones cognitivas claras. Sobre estas cuestiones Ponce Alfaro et al. 2003: 246 y 248.

87 Tal y como señala Frighetto 2006: 67, nota 215, con Vita Fruct. 11, 17-23 y VSPE, 12, 1-5.

88 Teniendo en cuenta una unidad de bebida estándar (UBE), que contiene $10 \mathrm{~g}$ de alcohol y se corresponde con una consumición de vino o cerveza: Gual Solé 2011: 346.

89 La poliomioneuropatía es la enfermedad neurológica más frecuente en los alcohólicos, comenzando por las extremidades inferiores de forma distal, cursando de forma progresiva con dolor, parastesia (alteraciones de la sensibilidad, hormigueos, entumecimientos), pudiendo producirse atrofia. En el sistema nervioso central, la patología más frecuente es la psicosis de Korsakov, en relación con el síndrome de Wernicke-Korsakoff (parálisis de los músculos oculares, ataxia, cambios de la personalidad, etc.): Gual Solé 2011: 357; Biesalski y Grimm 2012: 274; Mathies et al. 1980: 66. En este síndrome se produce una deficiencia de tiamina secundaria al alcoholismo crónico y los déficits nutricionales que se producen simultáneamente. «La evolución hacia deterioro mental es lenta pero progresiva y la evolución natural de la enfermedad es hacia el coma y la muerte» (Cáceres Anillo 2007: 139).

90 Laso Guzmán 2009: 83-86; Sarason y Sarason 2006: 444-457; Fauci et al. 2008: 2724-2729. 
comorbilidad, que el $37 \%$ de las personas que sufren trastornos de alcoholismo también padecen otro trastorno mental diagnosticable, como la esquizofrenia: en los hombres se relaciona con un riesgo ocho veces mayor del normal de padecer episodios psicóticos, y en las mujeres, un riesgo tres veces mayor de lo normal. Los índices más altos de comorbilidad se presentan en los casos de trastornos de la personalidad afectiva, de ansiedad y antisociales, llevando a un menor rendimiento laboral, a una mayor conflictividad con compañeros de trabajo, agresividad, accidentabilidad y suicidio. ${ }^{91}$

Por otra parte, el riesgo de que una persona desarrolle síndrome de dependencia alcohólica se halla relacionado con el nivel de exposición al alcohol y con la vulnerabilidad individual. Al mismo tiempo, el nivel de exposición al alcohol es influido por factores sociales, culturales y económicos, que determinan la accesibilidad al alcohol, tal y como señala A. Gual. ${ }^{92} \mathrm{El}$ hecho de que nuestro personaje sea un clérigo le permite tener acceso directo al alcohol.

Existen dos tipos de cursos clínicos del alcoholismo, uno de curso progresivo y otros de curso intermitente. En el primero, se sigue un proceso degenerativo, mientras que en el segundo hay alternancia de etapas, sin que sea necesario que haya empeoramiento progresivo. En el alcoholismo progresivo, Jellinek describió cuatro etapas, en las que a lo largo del tiempo se van sucediendo los diversos síntomas de la enfermedad..$^{93}$ Es este el patrón que parece que se ajusta más al relato de Valerio.

Desde el punto de vista de la clasificación de Cloninger, tal vez pudiéramos encontrarnos ante un caso de alcoholismo de Tipo II. Este incluye casos de comienzo temprano (adolescencia), presentando un componente genético marcado. Los enfermos son habitualmente de sexo masculino, comorbizando con trastornos de personalidad del tipo B. En ellos destacan el trastorno antisocial de la personalidad, trastorno depresivo mayor, agorafobia y fobia social, siendo muy conflictivos. Consumen alcohol buscando sentimientos de euforia, mostrándose agresivos fácilmente, puesto que el alcohol puede favorecer un estado de desinhibición que desactiva los frenos conductuales, dando lugar a embriagueces patológicas altamente violentas, con baja tolerancia ante las frustraciones. ${ }^{94}$

Cuando analizamos los detalles del comportamiento de Justo, y atendiendo a los criterios establecidos por Jellinek, podemos observar que se presentan algunos de los principales síntomas del alcoholismo. Así, encontramos una racionalización de la ingesta (un hábito); un escape geográfico (si es que admitimos el origen foráneo del personaje), posiblemente como consecuencia de las presiones sociales; conducta grandiosa con la ingestión; conductas agresivas; reinterpretación de las relaciones personales; descuido en la alimentación, que puede producir anorexia y desnutrición; ${ }^{95}$

91 Casas y Guardia 2002; Sarason y Sarason 2006: 446-447; Halsband y Socolsky 2008: 123-124; Gual Solé 2011: 357; Biesalski y Grimm 2012: 274-276; Hornstein 2008; Lagomarsino 2008; Lupo 2008; Alonso 2011; Valdés 2011.

92 Gual Solé 2011: 348.

93 Ibídem: 349.

94 Halsband y Socolsky 2008: 122; Casas y Guardia 2002: 206; Begoña Iglesias 2003: 195; Monrás Arnau 2003: 177.

95 Blinder y Chao 1994; Garner y Magana 2006. Consecuencias evidentes ya para los hipocráticos: Tratados Hipocráticos, Aforismos II, 1. degradación moral; cambios de carácter debidos a la ingesta alcohólica; cambio en las actitudes religiosas y hundimiento de los sistemas de racionalización, así como trastorno del sueño. ${ }^{96}$

La intoxicación aguda de alcohol puede desencadenar violencia, así como el síndrome de abstinencia, aunque no en todos los individuos se produce la misma reacción. En la clínica actual, las estadísticas muestran como el alcohol está implicado en una gran cantidad de delitos violentos y de asesinatos. Esto es debido a la existencia de una relación directa entre el abuso crónico del alcohol y lesiones cerebrales que, entre otras ubicaciones, afectan a los circuitos frontales que intervienen en la inhibición de los impulsos. Por otra parte, se ha comprobado la existencia de bajos niveles de serotonina en el sistema nervioso central en los alcohólicos impulsivos y violentos, así como un mayor nivel de testosterona libre en líquido cefalorraquídeo. Además de a estos factores fisiológicos y biológicos, la violencia vendría motivada por la necesidad de obtener la sustancia adictiva y al deterioro de la vida personal del adicto. ${ }^{97}$ Frecuentemente, la agresividad «aparece a los pocos minutos de la ingestión de alcohol en una cantidad que es insuficiente para provocar intoxicación en la mayor parte de la gente ${ }^{98}$

También existen embriagueces atípicas en el curso de una intoxicación etílica aguda (ingesta de alcohol por encima de la capacidad metabólica de la persona), cuyos cuadros se caracterizan -en alcoholemias superiores a 150 $\mathrm{mg} / \mathrm{dl}$ - por cursar con cambios graves y bruscos en el comportamiento, excitación psicomotora, agresividad física y verbal y, en ocasiones, ilusiones y/o alucinaciones. ${ }^{99}$

Por último, Justo puede padecer un trastorno metabólico denominado encefalopatía de Gayet-Wernicke, una enfermedad frecuente, de origen carencial, cuya etiología es el alcoholismo crónico. En esta patología, el déficit de vitamina $\mathrm{B}_{1}$ que produce la ingestión crónica del tóxico, unido a dietas insuficientes en las que predominan los hidratos de carbono y faltan proteínas - como las que debían ser corrientes en la época, especialmente entre los monjes-, y las alteraciones gástricas que impiden una correcta digestión y aprovechamiento, llegan a provocar un cuadro clínico en el que se asocian de manera variable los trastornos neurológicos y psíquicos. ${ }^{100}$

\section{CONCLUSIONES}

Si bien las historias de los dos monjes aquí analizadas no pueden desgajarse de ciertos tópicos al uso en la literatura cristiana de la Tardoantigüedad, creemos que existen suficientes elementos como para pensar que nos encontramos ante dos casos diferentes de alcoholismo crónico. No cabe duda de que se presentan como ejemplificadores de las conductas degradadas espiritualmente por el pecado de la

96 Gual Solé 2011: 350, tabla 24-5; Casas y Guardia 2002: 199-200; Biesalski y Grimm 2012: 274-276. En general, sobre los trastornos del comportamiento y de la personalidad, Hornstein 2008; Lagomarsino 2008; Lupo 2008; Alonso 2011; Valdés 2011.

97 Halsband y Socolsky 2008: $120-121$ y 123 . Estos hallazgos biológicos, son típicos de los alcohólicos del Tipo II.

98 Ochoa Mangado et al. 2009: 30.

99 Gual Solé 2011: 354.

100 Grau 2011: 341. 
gula y de la embriaguez. Pero creemos que se basan para su presentación en síntomas reales, conocidos por los autores de los textos. ${ }^{101}$ La existencia de un proceso de corrección en las Vitas de esta conducta que se ajusta perfectamente al procedimiento establecido por las reglas monásticas del momento, los comportamientos tipificados en las sanciones de estas normas, la exactitud en la descripción de las sintomatologías, distintas en los dos casos presentados, creemos que son elementos sustentadores suficientes para darle credibilidad al diagnóstico de alcoholismo crónico.

Las afecciones relacionadas con el alcohol se producen en personas de todos los estratos sociales. ${ }^{102}$ Pero en el período en estudio podría considerarse una patología asociada a los grupos sociales privilegiados. En cierta medida podríamos hablar de un cierto "estilo de vida monástico" y aún eclesiástico, al que podrían asociarse una serie de patologías que son consecuencia del mismo, unas patologías propias de grupos sociales con un alto nivel de vida. Grupos privilegiados que, con diferencias entre el clero regular y el secular, tienen mejor acceso a los recursos alimentarios, independientemente de las restricciones, más o menos rigoristas, que el ayuno impone en el calendario eclesiástico.

En definitiva nos encontraríamos ante lo que podríamos definir como "enfermedades de la opulencia» de la Tardoantigüedad. Se trata de entidades como la hiperostosis esquelética difusa idiopática (DISH) o Enfermedad de Forestier-Rotes Querol, una reumatología sistémica, que es una patología frecuente en personas de mediana y avanzada edad. El 25-50 \% de los casos presentan diabetes mellitus tipo II, siendo esta coincidencia posiblemente explicada por la constitución obesa ( $40 \%$ de los pacientes) y por su avanzada edad, además de tendencia a padecer síndrome metabólico y enfermedad coronaria. Igualmente también se halla en un $58 \%$ de los gotosos, que suelen presentar obesidad como factor asociado. ${ }^{103}$ Las artritis microcristalinas (podagra o gota) se suelen acompañar, aparte de las citadas alteraciones metabólicas, de hipertensión y arteriosclerosis. Ambas patologías están presentes en la Tardoantigüedad hispana: la DISH en restos paleopatológicos, la gota entre eclesiásticos tal y como se pone en evidencia en diferentes fuentes. ${ }^{104} \mathrm{~A}$ estas afecciones podríamos añadir las isquemias miocárdicas (infartos de miocardio), en relación directa con diversos factores de riesgo, como los ya mencionados

101 Esta es una característica común a muchas de las obras hagiográficas y religiosas de la época, donde los ejemplos y tópicos se basan, para darles credibilidad, en toda una serie de síntomas reales, presentes en las sociedades en que vivían. Sintomatologías muy diferentes entre sí, aunque se presenten para explicar temas comunes. De ahí, la posibilidad de realizar diagnósticos diferenciales sobre estas evidencias que presentan las fuentes (Menéndez Bueyes 2013). No estamos de acuerdo, en consecuencia, con aquellos que creen que no es posible utilizar estas fuentes para realizar un acercamiento a las condiciones de vida y salud de estas poblaciones (al respecto, ver ahora Marx-Wolf y Upson-Saia 2015).

102 Schuckit 2014: 2109.

103 De hecho, esta patología se ha asociado al monacato (alimentación con alto contenido calórico, vida sedentaria), por ser un hallazgo paleopatológico muy frecuente en los enterramientos medievales y modernos asociados a monasterios, si bien algunos estudios inciden más en el factor envejecimiento (Fuentes-Sánchez et al. 2016).

104 Menéndez Bueyes 2013: 85-86. Y no sólo en las fuentes hispanas, así, por ejemplo, la encontramos mencionada en Beda, Hist. Eccle. Gent. Angl. II.7.1. de la alimentación o diversas patologías, así como con las tensiones emocionales.

Otro grupo de patologías relacionadas con los eclesiásticos, en tanto que grupo privilegiado, son aquellas que tienen que ver con el estilo de vida del alto clero. Además de los padecimientos mencionados, que conllevan riesgo de padecer isquemias miocárdicas (infartos de miocardio), hemos de tener en cuenta las altas tensiones emocionales que conllevan estrés, depresiones y, en consecuencia, factor de riesgo añadido para afecciones cardiacas. En este sentido, nuestras fuentes evidencian que los eclesiásticos de alto rango estaban sometidos a fuertes presiones como consecuencia de los desencuentros en materia teológica, pero también tensiones relacionadas con el poder eclesiástico y político. EI XI Concilio de Toledo de 675 nos informa sobre estas discordias entre los obispos, que conocemos también por otras fuentes. ${ }^{105} \mathrm{Y}$ es que los obispos visigodos se comportaban como funcionarios regios, abordándose en los concilios cuestiones fundamentalmente de carácter político. De esta actividad política es una buena muestra el destacado papel que Sisberto, metropolitano de Toledo, tuvo en la conjura nobiliaria contra el rey Égica. ${ }^{106} \mathrm{~A}$ todas estas patologías podemos añadir el alcoholismo crónico, un alcoholismo propiciado por la accesibilidad al vino de los eclesiásticos por su propio trabajo. En la actualidad, el alcoholismo en el ámbito laboral se considera una inadaptación laboral «que tiende a degenerar en inadaptación social, por los graves efectos que produce en el propio trabajador alcohólico y en todo su entorno: problemas de integración, participación, comunicación, afectividad (amical, filial, de pareja). Problemas de etiquetamiento, marginación y exclusión sociales». ${ }^{107} \mathrm{Y}$ en este sentido, hemos de tener en cuenta que el consumo de alcohol es el responsable, en la clínica actual, de un veinte a un $30 \%$ de todos los casos de hipertensión arterial, por lo que el consumo regular de grandes cantidades es un factor de riesgo para el desarrollo de hipertensión, de accidente cerebrovascular y de miocardiopatía. ${ }^{108}$

\section{FUENTES}

Blanco García, V. y Campos Ruiz, J. 1971. Santos Padres Españoles I. Madrid: Biblioteca de Autores Cristianos.

Campos Ruiz, J. y Roca Meliá, I. 1971. Santos Padres Españoles II. Madrid: Biblioteca de Autores Cristianos.

Chrise, R. 1952. Ammianus Marcellinus, Res gestae, 3 vols. Cambridge (Massachusetts): Loeb Classical Library, Harvard University Press.

Cilleruelo, L. 1986. Obras Completas de San Agustín. VIII. Cartas (Io) 1-123. Madrid: Biblioteca de Autores Cristianos.

Codoñer Merino, C. 1972. El "De Viris Illustribus» de Ildefonso de Toledo. Estudio y edición crítica. Salamanca: Ediciones Universidad de Salamanca.

Díaz y Díaz, M. C. 2006. Valerio del Bierzo. Su persona. Su obra. León: Centro de Estudios e Investigación San Isidoro.

Grillone, A. 2017. Iordanes. Getica. París: Les Belles Lettres.

105 XI Concilio de Toledo, de 675, en su canon IV (Vives 1963: $357-$ 358). Muertes repentinas asociadas a eclesiásticos y a los ricos son mencionadas por nuestras fuentes, como en Isidoro, Sent. III. 62.4-5. Sobre estos temas Menéndez Bueyes 2013: 31.

106 Sobre estos temas, Díaz 2014: 1151-1153; Valverde Castro 2017: 128-138.

107 Benítez Hernández y León Fuentes 2003: 136.

108 Álvarez González y Del Río Gracia 2003: 120. 
King, J. E. 1930 Bede, Ecclesiastical History. Books 4-5. Lives of the Abbots. Letter to Egbert. Cambridge (Massachusetts)-Londres: Loeb Classical Library, Harvard University Press.

López Pereira, J. E. 2009. Continuatio Isidoriana Hispana. Crónica Mozárabe de 754. León: Centro de Estudios e Investigación San Isidoro.

Manzanero Cano, F.; García Arribas, I.; Arribas Hernáez, M. L.; Moure Casas, A. M. y Sancho Bermejo, J. L. 2010. Plinio el Viejo, Historia Natural. Libros XII-XVI. Madrid: Gredos.

Maya Sánchez, A. 1992. Vitas Sanctorvm Patrvm Emeretensivm. Turnholt: Brepols.

Migne, J.-P. 1862. Gregorius Magnus, Regulae Pastoralis Liber. Patrologiae cursus completes, series latina (MPL), vol. 77. Paris: Garnier Fratres, pp. 13-128A.

Miguel Franco, R. 2015. Braulio de Zaragoza, Epístolas. Madrid: Akal.

Rackham, H. 1968. Pliny. Natural History. Books 12-16. Cambridge (Massachusetts)-Londres: Loeb Classical Library, Harvard University Press.

Ramsey, B. 1997. John Cassian, The Conferences. Nueva York: Paulist Press.

Ramsey, B. 2000. John Cassian, The Institutes. Nueva York: Newman Press.

Valero, J. B. 2013-2015. San Jerónimo, Obras Completas. Epistolario, 2 vols. Madrid: Biblioteca de Autores Cristianos.

Vives, J. 1963. Concilios visigóticos e hispano-romanos. MadridBarcelona: Consejo Superior de Investigaciones Científicas.

Vogüé, A. de. 1978-1979-1980. Grégoire le Grand. Dialogues. 3 vols. París: Cerf.

Zanella, A. y Luiselli, B. 1991. Paolo Diacono, Storia dei Longobardi. Milano: Rizzoli.

\section{BIBLIOGRAFÍA}

Alonso, M. P. 2011. «Trastornos del control de los impulsos. A. Trastorno explosivo intermitente, cleptomanía, piromanía y tricotilomanía», en J. Vallejo Ruiloba (dir.), Introducción a la Psicopatología y la Psiquiatría: 385-402. Barcelona: Elsevier Masson.

Álvarez González, F. J. y Del Río Gracia, C. 2003. «Farmacología del alcohol», en E. García Usieto, S. Mendieta Cavides, G. Cervera Martínez y J. R. Fernández Hermida (coords.), Manua SET de Alcoholismo: 109-129. Madrid: Sociedad Española de Toxicomanías-Panamericana.

Amaral, R. 2009. A santidades habita o deserto. A haxiografía á luz do imaxinario social. Noia: Toxosoutos.

André, J.-M. 2006. La Médecine à Rome. Paris: Tallandier.

Bailey, L. K. 2007. "“These are not Men": Sex and Drink in the Sermons of Caesarius of Arles». Journal of Early Christian Studies 15 (1): 23-43. https://doi.org/10.1353/earl.2007.0011

Barona Vilar, J. L. 2003. "La evolución histórica y conceptual del alcoholismo», en E. García Usieto, S. Mendieta Cavides, G. Cervera Martínez y J. R. Fernández Hermida (coords.), Manual SET de Alcoholismo: 1-17. Madrid: Sociedad Española de Toxicomanías-Panamericana.

Begoña Iglesias, E. 2003. «Evaluación conductual de la dependencia alcohólica», en E. García Usieto, S. Mendieta Cavides, G. Cervera Martínez y J. R. Fernández Hermida (coords.), Manual SET de Alcoholismo: 187-211. Madrid: Sociedad Española de Toxicomanías-Panamericana.

Benítez Hernández, M. M. y León Fuentes, J. L. 2003. «Aspectos sociales de la evaluación diagnóstica del alcoholismo», en E. García Usieto, S. Mendieta Cavides, G. Cervera Martínez y J. R. Fernández Hermida (coords.), Manual SET de Alcoholismo: 131-159. Madrid: Sociedad Española de Toxicomanías-Panamericana.

Biesalski, H. K. y Grimm, P. 2012. Nutrición. Texto y Atlas. Madrid: Panamericana.

Blinder, B. J. y Chao, K. H. 1994. «Eating Disorders: A Historical Perspective», en L. A. Alexander-Mott y D. B. Lumsden (eds.), Understanding Eating Disorders: Anorexia Nervosa, Bulimia Nervosa, and Obesity: 3-36. Washington D. C.: Taylor \& Francis.
Brown, P. 1993. El cuerpo y la sociedad. Los hombres, las mujeres y la renuncia sexual en el cristianismo primitivo. Barcelona: Muchnik.

Brown, P. 2016. Por el ojo de una aguja. La riqueza, la caída de Roma y la construcción del cristianismo en Occidente (350-550 d. C.). Barcelona: Acantilado.

Büntgen, U.; Myglan, V. S.; Charpentier, F. et al. 2016. "Cooling and societal change during the Late Antique Little Ice Age from 536 to around 660 AD». Nature Geoscience 9: 231-236. https://doi.org/10.1038/ngeo2652

Cáceres Anillo, D. 2007. «Urgencias en alcoholismo: abordaje desde los centros de tratamiento de adicciones». Revista Española de Drogodependencias 32 (2): 131-148.

Casas, M. y Guardia, J. 2002. «Patología psiquiátrica asociada al alcoholismo». Adicciones 14 (Supl. 1): 195-219. https://doi.org/10.20882/adicciones.524

Cavero Domínguez, G. 2017. «Penal cloistering in Spain in the sixth and seventh centuries». Journal of Medieval Iberian Studies 9 (1): 1-24. https://doi.10.1080/17546559.2015.1119870.

Chavarría Arnau, A. 2004 "Monasterios, campesinos y villae en la Hispania visigoda: la trágica historia del abad Nancto», en C. Balmelle, P. Chevallier y G. Ripoll (eds.), Mélanges d'Antiquité Tardive. Studiola in honorem Noël Duval: 113-125. Turnhout: Brepols Publishers.

Clarysse, W. 2001. "Use and Abuse of Beer and Wine in Graeco-Roman Egypt», en K. Zimmermann (ed.), Punica, Libyca, Ptolemaica: Festschrift für Werner Huss: 159-166. Leuven: Peeters Publishers \& Departament of Oriental Studies.

Curado, B. 2004. La medicina en Mérida según la Vida de los Padres Emeritenses. Mérida: Museo Nacional de Arte Romano.

D'Arms, J. H. 1995. "Heavy Drinking and Drunkeness in the Roman World: Four Questions for Historians», en O. Murray y M. Tecusan (eds.), In vino veritas: 304-317. London: British School at Rome.

Dalby, A. 2003. Food in the Ancient World from A to Z. Abingdon, Oxon: Routledge.

Damjanov, I. 2010. Patología. Barcelona: Elsevier/Mosby.

Díaz, P. C. 1987. Formas económicas y sociales en el monacato visigodo. Salamanca: Ediciones Universidad de Salamanca.

Díaz, P. C. 2006. «El legado del pasado: reglas y monasterios visigodos y carolingios», en J. A. García de Cortázar y R. Teja (coords.), Monjes y Monasterios Hispanos en la Alta Edad Media: 11-31. Aguilar de Campoo: Fundación Santa María la Real, Centro de Estudios del Románico.

Díaz, P. C. 2014. "Concilios y obispos en la península ibérica (siglos VI-VIII)", en Chiese Locali e Chiese Regionali nell'Alto Medioevo, Spoleto, 4-9 aprile 2013. Settimane di Studio della Fonzazione Centro Italiano di Studi sull'Alto Medioevo LXI: 1095-1154. Spoleto: Centro Italiano di Studi Sull'Alto Medioevo.

Díaz, P. C. 2015. "Visigothic Monasticism Written Sources and Everyday Life», en O. Delouis y M. Mossakowska-Gaubert (eds.), La vie quotidienne des moines en Orient et en Occident (IV $-X^{e}$ siècle). Volume I. L'état des sources: 337-355. Athènes: Institut Français D’Archéologie Orientale. École Française d'Athènes.

Díaz, P. C. 2017. «Las fundaciones monásticas en la península ibérica (siglos VI-VIII)», en Monachesimi d'Oriente e d'Occidente nell'Alto Medioevo, Spoleto, 31 marzo-6 aprile 2016. Settimane di Studio della Fonzazione Centro Italiano di Studi sull'Alto Medioevo LXIV: 463-493. Spoleto: Centro Italiano di Studi Sull'Alto Medioevo.

Díez Manrique, J. F. 2011. Valerio del Bierzo. Ascetismo y orgullo. Santander: Real Academia de Medicina de Cantabria.

Domínguez del Val, U. 1981. Leandro de Sevilla y la lucha contra el arrianismo. Madrid: Editora Nacional.

Donahue, J. F. 2015. «Roman Dining», en J. Wilkins y R. Nadeau, (eds.), A Companion to Food in the Ancient World: 253-264. Oxford: Wiley Blackwell.

Eckardt, H.; Müldner, G. y Lewis, M. 2014. «People on the move in Roman Britain». World Archaeology 46 (4): 534-550. https://doi.org/10.1080/00438243.2014.931821

Fauci, A. S.; Braunwald, E.; Kasper, D. L.; Hauser, S. L.; Longo D. A.; Jameson, J. L. y Loscalzo, J. 2008. Harrison's Principles of Internal Medicine. 2 vols. New York: McGrawHill. 
Ferguson, J. A.; Suelzer, C. J.; Eckert, G. J.; Zhou, X.-H. y Dittus, S. 1996. "Risk Factors for Delirium Tremens Development». Journal of General Internal Medicine 11: 410-414.

Fernández Fernández, A. 2014. El comercio tardoantiguo (ss. IV-VII) en el Noroeste peninsular a través del registro cerámico de la ría de Vigo. Oxford: Archaeopress.

Ferngren, G. B. 2009. Medicine and Health Care in Early Christianity. Baltimore: The Johns Hopkins University Press.

Frighetto, R. 2006. Valerio del Bierzo. Autobiografía. Noia: Toxosoutos.

Fuentes-Sánchez, D.; López-Onaindia, D.; Dinarès, R. y Subirà, M. E. 2016. "Presence of Diffuse Idiopathic Skeletal Hyperostosis in an Avinganya Rural Population (Lleida, Iberian Peninsula)». Nexus: The Canadian Student Journal of Anthropology 24: 1-12.

Gargantilla Madera, P. 2016. Enfermedades que cambiaron la Historia. Madrid: La Esfera de los Libros.

Garner, D. M. y Magana, C. 2006. «Cognitive Vulnerability to Anorexia Nervosa», en L. B. Alloy y J. H. Riskind (eds.), Cognitive Vulnerbility to Emotional Disorders: 365-403. Erlbaum: Hillsdale, NJ.

Garnsey, P. 1999. Food and Society in Classical Antiquity. Cambridge: Cambridge University Press.

Gourevitch, D. 1991. «Bibliographie sur l'alcoolisme et la lute contre l'alcoolisme dans l'Antiquité gréco-romaine». Centre Jean Palerne. Lettre d information 18: 11-13.

Gourevitch, D. 1998. "Les societies antiques connoissaient-elles l'addiction?", en K. Malek (ed.), Les Passions Dangereuses. Addiction et conduits de dependence: 9-11. Paris: Flammarion.

Gourevitch, D. 2001. I giovani pazienti di Galeno. Per una patocenosi dell'impero romano. Roma-Bari: Laterza.

Gourevitch, D. y Demigneux, G. 2013. «Two historical case histories of acute alcoholism in the Roman Empire», en C. F. Goodey y M. Lynn Rose (eds.), Disabilities in Roman Antiquity. Disparate Bodies A Capite ad Calcem: 73-87. Leiden-Boston: Brill.

Grandal-D’Anglade, A.; Serrulla Rech, F.; Tomas Botella, V.; Pérez Rama, M.; Gómez, M. y Ramil González, E. 2015. «Vida y muerte de dos mujeres de Brigantium (NW de Iberia) mediante isótopos estables y antropología forense». Cuadernos del Laboratorio Xeolóxico de Laxe 38: 45-66.

Grau, A. 2011. "Trastornos exógenos u orgánicos», en J. Vallejo Ruiloba (dir.), Introducción a la Psicopatología y la Psiquiatría: 324-344. Barcelona: Elsevier Masson.

Gregoire, R. 1967. "Valeurs ascetiques et spiritualles de la Reg. Monach. et de la Reg. Com.». Bracara Augusta 21: 328-345.

Gual Solé, A. 2011. "Alcoholismo», en J. Vallejo Ruiloba (dir.) Introducción a la Psicopatología y la Psiquiatría: 345-358. Barcelona: Elsevier Masson.

Halsband, S. y Socolsky, P. 2008. "Agresividad y abuso de sustancias», en S. A. Halsband (comp.), Agresividad. Manifestaciones clínicas y tratamiento psicológico: 119-127. Buenos Aires: Palemos.

Harper, K. 2017. The Fate of Rome. Climate, Disease, and the End of an Empire. Princenton and Oxford: Princenton University Press.

Herrera Roldán, P. 2006. Pablo Diácono, Historia de los Longobardos. Cádiz: Universidad de Cádiz.

Hillgarth, J.H. 1980. "Popular Religion in Visigothic Spain», en E. James (ed.), Visigothic Spain. New Approaches: 5-37. Oxford: Oxford University Press.

Hornstein, C. 2008. "Agresividad. Agitación en demencias», en S. A. Halsband (comp.), Agresividad. Manifestaciones clínicas y tratamiento psicológico: 129-143. Buenos Aires: Palemos.

Jones, P. 2013. Veni, vidi, vici. Hechos, personajes y curiosidades de la antigua Roma. Barcelona: Crítica.

Knauer, C. M. 1976. «Mallory-Weiss Syndrome». Gastroenterology 71 (1): 5-8.

Kron, J. 2015. «Agriculture», en J. Wilkins y R. Nadeau, (eds.), A Companion to Food in the Ancient World: 160-170. Oxford: Wiley Blackwell.

Lagomarsino, A. J. 2008. "Violencia y trastornos del ánimo», en S.A. Halsband (comp.), Agresividad. Manifestaciones clínicas y tratamiento psicológico: 75-86. Buenos Aires: Palemos.

Lançon, B. 1990. «Vinolentia: I'ivrognerie en Gaule à la fin de l'Antiquité d'aprés les sources littéraires». Caesarodunum 24: 155-161.
Laso Guzmán, F. J. 2009. Diagnóstico diferencial en medicina interna. Barcelona: Elsevier.

Laso Guzmán, F. J. 2010. Introducción a la Medicina Clínica. Fisiopatología y semiología. Barcelona: Elsevier/Masson.

Le Goff, J. y Truong, N. 2005. Una historia del cuerpo en la Edad Media. Barcelona: Paidós.

Leigh, M. 2015. «Food in Latin Literature», en J. Wilkins y R. Nadeau, (eds.), A Companion to Food in the Ancient World: 43-52. Oxford: Wiley Blackwell.

Lesniewski, K. 2017. Las enfermedades del espíritu. Diagnóstico y tratamiento en clave cristiana. Salamanca: Sígueme.

Lupo, Ch. 2008. «Trastorno explosivo intermitente», en S.A. Halsband (comp.), Agresividad. Manifestaciones clínicas y tratamiento psicológico: 103-118. Buenos Aires: Palemos.

Manrique Campillo, A. 1969. "La Regla de S. Agustín en España durante los primeros siglos de su existencia». Ciudad de Dios 182: 485-513.

Martínez Moneo, M.; Madoz Gúrpide, C. y Otaño, M. 2005. «Delirium Tremens», en Libro electrónico de Temas de Urgencia. Servicio Navarro de Salud.

<http://www.cfnavarra.es/salud/PUBLICACIONES/Libro\%20elec tronico\%20de\%20temas\%20de\%20Urgencia/17.Psiquiatricas/ Indice\%20Psiquiatricas.pdf> (consultado el 12 de noviembre de 2017).

Marx-Wolf, H. y Upson-Saia, K. 2015. «The State of the Question: Religión, Medicine, Disability, and Health in Late Antiquity». Journal of Late Antiquity 8 (2): 257-272. https://doi.org/10.1353/jla.2015.0029

Mathies, H.; Otte, P.; Villiaumey, J.; St. Dixon, A. y Rotés Querol, J. 1980. Classification des affections de l'appareil locomoteur. Basilea: EULAR Publishers.

Mausbach, J. y Ermecke, G. 1974. Teología Moral Católica. III. Moral Especial. Pamplona: Ediciones Universidad de Navarra.

Menéndez Bueyes, L. R. 2013. Medicina, enfermedad y muerte en la España Tardoantigua. Un acercamiento histórico a las patologías de las poblaciones de la época tardorromana e hispanovisigoda (siglos IV-VII). Salamanca: Ediciones Universidad de Salamanca.

Monrás Arnau, M. 2003. «Evaluación psicológica en el diagnóstico del alcoholismo», en E. García Usieto, S. Mendieta Cavides, G. Cervera Martínez y J. R. Fernández Hermida (coords.), Manual SET de Alcoholismo: 161-186. Madrid: Sociedad Española de Toxicomanías-Panamericana.

Mundó, A. 1957. "Il monachesimo nella Penisola Iberica fino al sec. VII», en Settimana di Studio del Centro Italiano di Studio sull'Alto Medioevo IV, 1956: 73-117. Spoleto: Centro Italiano di Studi Sull'Alto Medioevo.

Ochoa Mangado, E.; Madoz-Gúrpide, A. y Vicente Muelas, N. 2009. "Diagnóstico y tratamiento de la dependencia de alcohol». Medicina y Seguridad del Trabajo 55 (214): 26-40. https://doi.org/10.4321/s0465-546x2009000100003

Orlandis, J. 1964. «La disciplina eclesiástica española sobre la vida eremítica». Ius Canonicum 4 (1): 147-164.

Pöll, W. 1969. Psicología de la religión. Barcelona: Herder.

Ponce Alfaro, G.; Jiménez-Arriero, M. A. y Rubio Valladolid, G. 2003. «Aspectos médicos de la evaluación de la dependencia alcohólica. Indicadores clínicos y medidas fisiológicas», en E. García Usieto, S. Mendieta Cavides, G. Cervera Martínez y J. R. Fernández Hermida (coords.), Manual SET de Alcoholismo: 243-258. Madrid: Sociedad Española de Toxicomanías-Panamericana.

Reverte Comas, J. M. 1991. Antropología Forense. Madrid: Ministerio de Justicia.

Rodríguez Castillo, H. 2005. Los monasterios dúplices en Galicia en la Alta Edad Media. Noia: Toxosoutos.

Rousselle, A. 1989. Porneia. Del dominio del cuerpo a la privación sensorial. Barcelona: Ediciones Península.

Royo Marín, A. 1988. Teología de la Perfección Cristiana. Madrid: Biblioteca de Autores Cristianos.

Rozman, C. 2010. Medicina Interna. Barcelona: Elsevier.

Sarason, I. G. y Sarason, B. R. 2006. Psicopatología. Psicología anormal: el problema de la conducta inadaptada. México: Pearson. 
Saunders, J. B. y Janca, A. 2000. «Delirium tremens: its aetiology, natural history and treatment». Current Opinion in Psychiatry 13 (6): 629-633. https://doi.org/10.1097/00001504-200011000-00027

Schuckit, M. A. 2014. "Recognition and Management of Withdrawa Delirium (Delirium Tremens)». The New England Journal of Medicine 371: 2109-2113. https://doi.org/10.1056/nejmra1407298

Smith, D. E. 2015. "Food and Dining in Early Christianity», en J. Wilkins y R. Nadeau, (eds.), A Companion to Food in the Ancient World: 357-364. Oxford: Wiley Blackwell.

Spaete, J. P. y Branch, M. S. 2016. "Mallory-Weiss Syndrome», en A. D. Pryor, Th. N. Pappas y M. S. Branch (eds.), Gastrointestina Bleeding. A Practical Approach to Diagnosis and Management: 81-87. Springer, Cham: Springer International Publishing.
Valdés, M. 2011. «Trastornos de la personalidad», en J. Vallejo Ruiloba (dir.), Introducción a la Psicopatología y la Psiquiatría: 286-295. Barcelona: Elsevier Masson.

Valverde Castro, R. 2017. Los viajes de los reyes visigodos de Toledo (531-711). Madrid: La Ergástula.

Wilkins, J. 2015. "Medical Literature, Diet, and Health», en J. Wilkins y R. Nadeau, (eds.), A Companion to Food in the Ancient World: 59-66. Oxford: Wiley Blackwell.

Williams, M. H. 2006. The Monk and the Book. Jerome and the Making of Christian Scholarship. Chicago-London: The University of Chicago Press. 